\title{
Impact of Spontaneous Breathing Trial on Work of Breathing Indices Derived From Esophageal Pressure, Electrical Activity of the Diaphragm, and Oxygen Consumption in Children
}

\author{
Guillaume Mortamet, Nicolas Nardi, Véronique Groleau, Sandrine Essouri, Brigitte Fauroux, \\ Philippe Jouvet, and Guillaume Emeriaud
}

\begin{abstract}
BACKGROUND: The present study aimed to characterize the behavior of 3 components of respiratory muscle function during mechanical ventilation weaning in children to better understand the respective impact of a spontaneous breathing trial on ventilatory mechanical action (esophageal pressure $\left[P_{e s}\right]$, ventilatory demand (electrical activity of the diaphragm $\left.\left[E A_{d i}\right]\right)$, and oxygen consumption. METHODS: This was a prospective single-center study. All children $>1$ months and $<18$ y old who were intubated and on mechanical ventilation, and who were hospitalized in the pediatric ICU were eligible. Subjects considered as ready to extubate were included. Simultaneous recordings of oxygen consumption, $P_{\mathrm{es}}$, and $\mathbf{E A _ { \mathrm { di } }}$ were performed during 3 steps: before, during, and after the spontaneous breathing test. RESULTS: Twenty subjects (median age, $5.5 \mathrm{mo}$ ) were included. Half of them were admitted for a respiratory cause. The increase in $P_{\text {es }}$ swings and esophageal pressure-time product during the spontaneous breathing trial was not significant $(P=.33$ and $P=.75$, respectively), and a similar trend was observed with peak $\mathbf{E A}_{\mathrm{di}}(P=.06)$. Oxygen consumption obtained by indirect calorimetry was stable in the 3 conditions $(P=.98)$. CONCLUSIONS: In these children who were critically ill, a spontaneous breathing trial induced a moderate and nonsignificant increase in work of breathing, as reflected by the respiratory drive with $\mathbf{E A}_{\mathrm{di}}$ and respiratory mechanics with $\mathbf{P}_{\mathrm{es}}$. However, indirect calorimetry did not seem to be a sensitive tool to assess respiratory muscle function during the weaning phase in children who were on mechanical ventilation, especially when work of breathing was slightly increased. Key words: mechanical ventilation; indirect calorimetry; work of breathing; weaning; pediatric intensive care unit. [Respir Care 2019;64(5):509-518. (C) 2019 Daedalus Enterprises]
\end{abstract}

\section{Introduction}

Respiratory failure is the leading cause of admissions in the pediatric ICU and mechanical ventilation is first-line

Drs Mortamet, Nardi, Jouvet, and Emeriaud are affiliated with the Pediatric Intensive Care Unit, Centre Hospitalier Universitaire (CHU) SainteJustine, Montreal, Québec, Canada. Drs Mortamet, Nardi, Groleau, Essouri, Fauroux, Jouvet, and Emeriaud are affiliated with Université de Montréal, Montréal, Québec, Canada. Drs Mortamet and Fauroux are affiliated with Université de Paris-Est, Créteil, France. Drs Mortamet and Fauroux are affiliated with Unité Institut National de la Santé et de la Recherche Médicale (INSERM) U955, Créteil, France. Dr Groleau is affiliated with the Department of Gastroenterology, Hepatology and Nutrition, CHU Sainte-Justine, Montreal, Québec, Canada. Dr Essouri is affiliated with the Department of Pediatrics, CHU Sainte-Justine, Mon- treatment. Although mechanical ventilation is often lifesaving, it can be associated with complications, such as ventilator-induced lung injury, ${ }^{1}$ nosocomial infection, airway trauma, and severe diaphragmatic dysfunction. ${ }^{2}$ It, therefore, is important that mechanical ventilation be distreal, Québec, Canada. Dr Fauroux is affiliated with the Pediatric Non-
invasive Ventilation and Sleep Unit, Hôpital Necker, Paris, France.

The study was supported by the Réseau en Santé Respiratoire du Québec, the Assistance Publique des Hôpitaux de Paris, and the Fondation SainteJustine.

This work was performed in CHU Sainte-Justine, Pediatric Intensive Care Unit, Montreal, Quebec, Canada. 
continued as soon as possible, that is, as soon as the patient is capable of spontaneous breathing.

\section{See the Related Editorial on Page 614}

During the weaning phase of mechanical ventilation, the ability of the respiratory muscles to cope with the imposed load is challenged. ${ }^{3}$ The assessment of respiratory muscle function during the weaning process could help to predict extubation success and optimize its timing. ${ }^{4}$ Different tools are available to monitor different components of respiratory muscle function during the weaning phase. Esophageal pressure $\left(\mathrm{P}_{\mathrm{es}}\right)$ measurement is the reference method to measure the pressure generated by the patient's inspiratory muscles and has been shown to be a good method to predict weaning outcome. ${ }^{5,6}$

The electrical activity of the diaphragm $\left(\mathrm{EA}_{\mathrm{di}}\right)$ reflects the patient's ventilatory drive, and it has been used to monitor diaphragm activity during weaning trials. ${ }^{7}$ The neuromechanical or neuroventilatory efficiency of the respiratory system can be estimated by the ratio of the muscle pressure or the ventilatory volume divided by the corresponding $\mathrm{EA}_{\mathrm{di}}{ }^{8}$ Moreover, oxygen consumption $\left(\dot{\mathrm{V}}_{\mathrm{O}_{2}}\right)$ has been shown to change on adaptations of mechanical ventilation parameters and modes because the oxygen cost of breathing reflects the output of the respiratory muscles. ${ }^{9}$

Whereas, in normal subjects, the portion of $\dot{\mathrm{V}}_{\mathrm{O}_{2}}$ assigned to the respiratory load $\dot{\mathrm{V}}_{\mathrm{O}_{2}}$ accounts for 1 to $3 \%$ of the whole body $\dot{\mathrm{V}}_{\mathrm{O}_{2}},{ }^{10}$ this percentage can be considerably higher in patients being weaned from ventilation. ${ }^{11,12}$ Indirect calorimetry, which provides $\dot{\mathrm{V}}_{\mathrm{O}_{2}}$ continuously at the bedside, could be an attractive tool to assess the respiratory muscle function because this could be a reliable and less invasive method of estimating the change in the work

Dr Mortamet presented this work at the National Congress on Intensive Care Medicine, held on January 23-26, 2018, in Paris, France.

Dr Jouvet discloses relationships with the Fonds de Recherche du Québec Santé, Ministry of Health, Sainte-Justine Hospital, Sage Therapeutic, Medunik, and Covidien. Dr Emeriaud discloses relationships with the Fonds de Recherche du Québec - Santé, and Maquet Critical Care. Dr Fauroux discloses relationships with Association Française contre les Myopathies, Assistance Publique-Hôpitaux de Paris, Inserm, Université Paris Descartes, ADEP Assistance, ASV Santé, S2A Santé, and IP Santé Domicile. The remaining authors have disclosed no conflicts of interest.

Supplementary material related to this paper is available at http:// www.rcjournal.com.

Correspondence: Guillaume Mortamet MD PhD, Pediatric Intensive Care Unit, CHU Sainte-Justine, 3175 Côte Sainte-Catherine, Montreal, Quebec H3T 1C5, Canada. E-mail: mortam@hotmail.fr.

DOI: $10.4187 /$ respcare.06351

\section{QUICK LOOK}

\section{Current Knowledge}

The assessment of respiratory muscle function during the weaning process could help to predict extubation success and optimize its timing. Different parameters (such as esophageal pressure, electrical activity of the diaphragm, and oxygen consumption measured by indirect calorimetry) are available to monitor various components of respiratory muscle function during the weaning phase.

\section{What This Paper Contributes to Our Knowledge}

In children who were critically ill, a spontaneous breathing trial induced a moderate and nonsignificant increase in work of breathing, as reflected by the respiratory drive monitored with electrical activity of the diaphragm and by the respiratory mechanics measured with esophageal pressure. However, indirect calorimetry, which measures oxygen consumption, did not seem to be a sensitive tool to assess respiratory muscle function during the weaning phase in children on mechanical ventilation.

of breathing. However, pediatric data in this field are lacking, especially about the reliability and reproducibility of indirect calorimetry. The present study aimed to characterize the behavior of 3 components of respiratory muscle function during mechanical ventilation weaning in children to better understand the respective impact of a spontaneous breathing trial (SBT) on $\mathrm{P}_{\mathrm{es}}, \mathrm{EA}_{\mathrm{di}}$, and $\dot{\mathrm{V}}_{\mathrm{O}_{2}}$.

\section{Methods}

This was a prospective study, conducted in the pediatric ICU of Centre Hospitalier Universitaire (CHU) SainteJustine, a university affiliated pediatric hospital, from November 2016 to June 2017. The study protocol was approved by the ethics committee of CHU Sainte-Justine, and written informed consent was obtained from the parents or legal tutor.

\section{Subjects}

Consecutive children ages between 1 month and 18 y admitted to the pediatric ICU, intubated, and on mechanical ventilation were eligible. The screening was performed by the research assistants Mariana Dumitrascu, Mary-Ellen French, and Jouher Nait every working day. Eligible patients were included if they were deemed to be ready for an extubation readiness test as per the attending team, provided the research team and the equipment were available. Patients were excluded if they had one of the fol- 
lowing criteria: contraindications to the placement of a new nasogastric tube, hemodynamic instability, severe respiratory instability, axillary temperature $>38^{\circ} \mathrm{C}$, cuff leaks $>10 \%$, nitrite oxide therapy, ventilation with high frequency oscillation, or if a limitation of life support treatments was discussed or decided. Detailed inclusion and exclusion criteria are given in the supplementary material (see the supplementary materials at http://www.rcjournal. com).

\section{Protocol and Data Recording}

$\mathrm{P}_{\mathrm{es}}, \mathrm{EA}_{\mathrm{di}}$, and $\dot{\mathrm{V}}_{\mathrm{O}_{2}}$ data were monitored to characterize respiratory muscle function. $\mathrm{P}_{\mathrm{es}}$ and $\mathrm{EA}_{\mathrm{di}}$ were obtained simultaneously by a specific modified 8 French EA $_{\mathrm{di}}$ catheter (NeuroVent Research, Toronto, Ontario, Canada) equipped with both microelectrodes (for $\mathrm{EA}_{\mathrm{di}}$ monitoring) and an esophageal balloon (for $\mathrm{P}_{\mathrm{es}}$ monitoring) (see the supplementary materials at http://www.rcjournal.com), installed $30 \mathrm{~min}$ before measurement. The catheter was connected to a Servo-i ventilator (Maquet, Solna, Sweden), to gather the $\mathrm{EA}_{\mathrm{di}}$ signal. The correct position of the catheter was checked with a specific positioning screen on the Servo-i by following the company recommendation. ${ }^{13}$ In that position, the middle electrodes of the array are very close to the median diaphragm position. The balloon, which is located $1 \mathrm{~cm}$ above the upper electrode, therefore, was in the lower esophagus. $\mathrm{P}_{\mathrm{es}}$ and $\mathrm{EA}_{\mathrm{di}}$ signals were simultaneously recorded by using an acquisition system (NeuroVent Monitor XIII) and displayed and analyzed by using specific software (NeuroVent Research).

$\dot{\mathrm{V}}_{\mathrm{O}_{2}}$ and resting energy expenditure were measured by a portable indirect calorimeter (Vmax Encore, CareFusion, Yorba Linda, California), which was connected $30 \mathrm{~min}$ before measurement. Gas and pressure were calibrated according to the manufacturer's instructions. All data were measured during 3 periods of 30 min each: before, during, and after an SBT in CPAP. The subjects were supine, with the head of bed elevated to $30^{\circ}$, and no or light sedation, according to the attending physician's instructions.

Demographic data and subjects characteristics, including age, sex, weight, time of measurements, admission diagnostic, and comorbidities, and Pediatric Risk of Mortality and Pediatric Logistic Organ Dysfunction scores were collected. Rapid shallow breathing index is defined as the ratio of breathing frequency to tidal volume $\left(\mathrm{V}_{\mathrm{T}}\right)$. Predicted energy expenditure was calculated according to the Schofield equations $(\mathrm{kcal} / \mathrm{d}$ ) (see the supplementary materials at http://www.rcjournal.com). Clinical indices of increased work of breathing and comfort of the subject, assessed with the COMFORT behavior scale, were gathered during the 3 periods. The sedation level was assessed with the sedation score described by Randolph et al, ${ }^{14}$ which was adapted to include dexmedetomidine accord- ing to the study performed by Eren et al. ${ }^{15}$ One point was given for morphine or midazolam equivalents of $0.1 \mathrm{mg} / \mathrm{kg}$. Pediatric ICU outcome data included the following: SBT success or failure, extubation success or failure (as defined by the need to re-intubate in the $48 \mathrm{~h}$ after extubation), and duration of mechanical ventilation.

\section{Data Analysis}

For $\mathrm{P}_{\mathrm{es}}$ and $\mathrm{EA}_{\mathrm{di}}$ recordings, after elimination of the cycles with artifacts, such as coughing or esophageal spasms, at least 20 consecutive breath cycles in the 3 different respiratory conditions were used for subsequent analysis. $\mathrm{P}_{\mathrm{es}}$-time product $\left(\mathrm{PTP}_{\mathrm{es}}\right)$ was obtained by measuring the area under the $\mathrm{P}_{\mathrm{es}}$ signal between the onset of inspiration and the end of inspiration as determined on $\mathrm{EA}_{\mathrm{di}}$ tracing. PTP was also expressed per minute by multiplying the PTPs per breath by the breathing frequency $\left(\mathrm{PTP}_{\mathrm{es}} / \mathrm{min}\right)$. Neuromechanical and neuroventilatory efficiencies were assessed by the ratio of swing $\mathrm{P}_{\mathrm{es}}$ to peak $\mathrm{EA}_{\mathrm{di}}$, and $\mathrm{V}_{\mathrm{T}}$ to peak $\mathrm{EA}_{\mathrm{di}}$, respectively.

The mean $\dot{\mathrm{V}}_{\mathrm{O}_{2}}$ and resting energy expenditure were calculated during the 3 periods. Data from the first $10 \mathrm{~min}$ and from periods of documented physical movement or nursing care, such as endotracheal suctioning, were excluded. The steady state was defined as 10 consecutive minutes during which $\dot{\mathrm{V}}_{\mathrm{O}_{2}}$ and carbon dioxide production vary less than $\pm 10 \%$, as previously described. ${ }^{16}$ The respiratory load $\dot{\mathrm{V}}_{\mathrm{O}_{2}}$ was defined as the difference between $\dot{\mathrm{V}}_{\mathrm{O}_{2}}$ during SBT and $\dot{\mathrm{V}}_{\mathrm{O}_{2}}$ under conventional mechanical ventilation.

\section{Statistical Analysis}

Data were expressed as median values (interquartile range [IQR]) for continuous variables and as number and/or frequency $(\%)$ for categorical data. Differences for categorical variables were tested by using the chi-square or the Fisher exact test (when expected frequencies were $<5$ ). Differences in continuous variables were assessed by using the non-parametric Mann-Whitney test or the paired $t$ test, depending on the variable distribution. Repeated measures analysis of variance was used to compare the different conditions (before, during, and after SBT in CPAP) on the different variables. Pearson correlation coefficient $(\mathrm{R})$ and determination coefficient $\left(\mathrm{R}^{2}\right)$ were used to evaluate the correlation between changes in swing $\mathrm{P}_{\mathrm{es}}, \mathrm{PTP}_{\mathrm{es}}$, $\mathrm{EA}_{\mathrm{di}}$, and $\dot{\mathrm{V}}_{\mathrm{O}_{2}}$. All $P$ values were 2-tailed and considered significant if $P<.05$. Statistical analyses were performed by using SPSS 24.0 (SPSS, Chicago, Illinois). Details regarding the sample size are given in the supplementary material (see the supplementary materials at http:// www.rcjournal.com). 


\section{Results}

\section{Study Population}

During the study period, 568 patients were admitted to the pediatric ICU, and 280 were mechanically ventilated. Thirty-one patients were eligible and approached by the study team. Five parents or guardians did not consent to the study, whereas 4 patients were extubated before inclusion. In 2 subjects, measurements were not performed due to clinical deterioration. In total, 20 subjects were enrolled (10 boys), with a median age of 5.5 (IQR, 2-64) months. The subjects' characteristics are presented in Table 1 . They were studied 7 (IQR, 3-11) d after initiation of mechanical ventilation. The main reason for admission to the pediatric ICU was respiratory failure ( $n=10[50 \%])$, and 3 subjects $(15 \%)$ were admitted after surgery. Before SBT, the median COMFORT score was 14 (IQR, 12-16). Five subjects (25\%) received intermittent analgesic treatments only, whereas $5(25 \%)$ received both sedative and analgesics agents with a continuous infusion. In 2 subjects, $\mathrm{EA}_{\mathrm{di}}$ could not be measured due to technical problems and, for another subject, the measurements from indirect calorimetry were inaccurate due to air leaks of $>10 \%$ that occurred after inclusion. All the subjects were on the same settings after SBT as before SBT.

\section{Breathing Pattern and Work of Breathing During SBT}

As detailed in the Table 2, the breathing frequency tended to increase during the SBT, although this did not reach significance $(P=.23)$. No clear changes in $\mathrm{V}_{\mathrm{T}}$, minute ventilation, and the rapid shallow breathing index were observed. Unexpectedly, the increase in $\mathrm{P}_{\mathrm{es}}$ swings and $\mathrm{PTP}_{\mathrm{es}} / \mathrm{min}$ during the SBT was not significant $(P=.33$ and $P=.75$, respectively) (Fig. 1). $\mathrm{P}_{\mathrm{es}}$ swings increased by at least $10 \%$ during SBT in 14 subjects (70\%). A similar trend was observed with peak $\mathrm{EA}_{\mathrm{di}}(P=.059)$. Neuromechanical and neuroventilatory efficiency did not change significantly before, during, or after SBT. We did not observe any association between $\mathrm{P}_{\mathrm{es}}$ and $\mathrm{EA}_{\mathrm{di}}$ changes and the level of comfort or the sedation score.

\section{Variables Measured By Indirect Calorimeter}

$\dot{\mathrm{V}}_{\mathrm{O}_{2}}$ obtained by indirect calorimetry was stable in the 3 conditions $(P=.98)$. In 10 subjects $(50 \%), \dot{\mathrm{V}}_{\mathrm{O}_{2}}$ decreased during SBT. Resting energy expenditure and the respiratory load $\dot{\mathrm{V}}_{\mathrm{O}_{2}}$ patterns did not differ according to the COMFORT and sedation score. Predicted resting energy expenditure was overestimated compared with the measured resting energy expenditure (47 [40-54] kcal/kg/d vs 23 [21-29] kcal/kg/d, $P<.001$ ) and the median (IQR)
Table 1. Characteristics of the Study Population

\begin{tabular}{|c|c|}
\hline Characteristic & Results \\
\hline Age, median (IQR) mo & $5.5(2-64)$ \\
\hline Weight, median (IQR) kg & $6.4(4.1-17.6)$ \\
\hline Boys, $n(\%)$ & $10(50)$ \\
\hline Predicted REE, median (IQR) kcal $/ \mathrm{kg}$ & $47(40-54)$ \\
\hline $\begin{array}{l}\text { Days between admission and inclusion, } \\
\text { median (IQR) }\end{array}$ & $7(3-12)$ \\
\hline $\begin{array}{l}\text { Days between mechanical ventilation initiation } \\
\text { and inclusion, median (IQR) }\end{array}$ & $7(3-11)$ \\
\hline \multicolumn{2}{|l|}{ Main reasons for pediatric ICU admission, $n(\%)$} \\
\hline Respiratory failure & $10(50)$ \\
\hline Hemodynamic failure & $4(20)$ \\
\hline Neurologic disorder & $3(15)$ \\
\hline Postoperative admission & $3(15)$ \\
\hline \multicolumn{2}{|l|}{ Chronic condition, $n(\%)$} \\
\hline Respiratory disease & $7(35)$ \\
\hline Cardiac disease & $4(20)$ \\
\hline Neurologic disease & $3(15)$ \\
\hline \multicolumn{2}{|l|}{ Clinical status at baseline, median (IQR) } \\
\hline PIM-2 score (on admission day) & $2.8(0.6-18.8)$ \\
\hline PELOD score & $7(1-19)$ \\
\hline Temperature, ${ }^{\circ} \mathrm{C}$ & $36.9(36.5-37.2)$ \\
\hline $\mathrm{pH}$ & $7.38(7.35-7.40)$ \\
\hline $\mathrm{P}_{\mathrm{aCO}_{2}}, \mathrm{~mm} \mathrm{Hg}$ & $47.4(44.2-53.3)$ \\
\hline $\mathrm{HCO}_{3-}, \mathrm{mm} \mathrm{Hg}$ & $28.0(26.0-30.8)$ \\
\hline Lactate, $\mathrm{mmol} / \mathrm{L}$ & $1.4(0.9-1.8)$ \\
\hline Hemoglobin, g/L & $10.3(9.6-11.1)$ \\
\hline \multicolumn{2}{|l|}{ Ventilator modes and settings } \\
\hline NAVA, $n$ & 7 \\
\hline NAVA level, median (IQR) $\mathrm{cm} \mathrm{H}_{2} \mathrm{O} / \mu \mathrm{V}$ & $0.5(0.3-0.5)$ \\
\hline PSV,$n$ & 9 \\
\hline PSV, median (IQR) $\mathrm{cm} \mathrm{H}_{2} \mathrm{O}$ & $9(6-11)$ \\
\hline $\mathrm{PC}, n$ & 4 \\
\hline IPAP, median (IQR) $\mathrm{cm} \mathrm{H}_{2} \mathrm{O}$ & $14(11-15)$ \\
\hline PEEP, median (IQR) $\mathrm{cm} \mathrm{H}_{2} \mathrm{O}$ & $5(5-6)$ \\
\hline $\mathrm{F}_{\mathrm{IO}_{2}}$, median $(\mathrm{IQR})$ & $30(25-40)$ \\
\hline \multicolumn{2}{|l|}{ ETT } \\
\hline ETT size, median (IQR) mm ID & $3.5(3.5-4.5)$ \\
\hline Cuffed ETT, $n(\%)$ & $18(90)$ \\
\hline Air leakage around ETT, median (IQR) \% & $5(2-7)$ \\
\hline \multicolumn{2}{|l|}{ Sedation status } \\
\hline COMFORT score, median (IQR) & $14(12-16)$ \\
\hline Sedation score, median (IQR) & $12(5-26)$ \\
\hline Continuous intravenous sedation, $n(\%)$ & $14(70)$ \\
\hline Analgesic bolus only, $n(\%)$ & $5(25)$ \\
\hline \multicolumn{2}{|l|}{ Outcome } \\
\hline SBT failure, $n(\%)$ & $0(0)$ \\
\hline $\begin{array}{l}\text { Time between SBT and first extubation, } \\
\text { median (IQR) } h\end{array}$ & $18(1.5-43.5)$ \\
\hline $\begin{array}{l}\text { Re-intubation in the } 48 \mathrm{~h} \text { after extubation, } \\
n(\%)\end{array}$ & $2(10)$ \\
\hline \\
\hline \multicolumn{2}{|l|}{$\mathrm{IQR}=$ interquartile range } \\
\hline \multicolumn{2}{|l|}{$\mathrm{REE}=$ resting energy expenditure } \\
\hline \multicolumn{2}{|l|}{$\mathrm{PIM}=$ pediatric index of mortality } \\
\hline \multicolumn{2}{|l|}{ PELOD = pediatric logistic organ dysfunction } \\
\hline \multicolumn{2}{|l|}{ NAVA = neurally adjusted ventilatory assist } \\
\hline \multicolumn{2}{|l|}{ PSV $=$ pressure support ventilation } \\
\hline \multicolumn{2}{|l|}{$\mathrm{PC}=$ pressure control } \\
\hline \multicolumn{2}{|l|}{ IPAP = Inspiratory positive airway pressure } \\
\hline \multicolumn{2}{|l|}{$\mathrm{ETT}=$ endotracheal tube } \\
\hline \multicolumn{2}{|l|}{$\mathrm{ID}=$ internal diameter } \\
\hline $\mathrm{SBT}=$ spontaneous breathing trial & \\
\hline
\end{tabular}


Table 2. Clinical Status and Respiratory Muscle Assessment Before, During, and After SBT

\begin{tabular}{|c|c|c|c|c|}
\hline \multirow{2}{*}{ Parameter } & \multicolumn{3}{|c|}{ SBT, Median (IQR) } & \multirow{2}{*}{$P$} \\
\hline & Before & During & After & \\
\hline \multicolumn{5}{|l|}{ Respiratory status } \\
\hline $\mathrm{S}_{\mathrm{pO}_{2}}$ & $99(96-100)$ & $99(95-100)$ & $97(95-100)$ & .79 \\
\hline Measured frequency, breaths/min & $29(22-31)$ & $35(26-40)$ & $30(25-37)$ & .23 \\
\hline $\mathrm{V}_{\mathrm{T}}, \mathrm{mL} / \mathrm{kg}$ & $7.1(5.4-7.8)$ & $6.4(4.4-7.8)$ & $7.8(5.1-8.1)$ & .89 \\
\hline$\dot{\mathrm{V}}_{\mathrm{E}}, \mathrm{L} / \mathrm{min}$ & $1.5(0.9-2.8)$ & $1.7(1.1-2.8)$ & $1.6(0.9-3.2)$ & .76 \\
\hline RSBI $\left(\mathrm{f} / \mathrm{V}_{\mathrm{T}}\right)$, breaths $/ \mathrm{min} / \mathrm{mL} / \mathrm{kg}$ & $4.1(3.1-6.3)$ & $5.4(4.0-7.3)$ & $5.0(3.9-6.1)$ & .76 \\
\hline COMFORT score & $14(12-16)$ & $14(12-16)$ & $13(12-16)$ & .86 \\
\hline \multicolumn{5}{|l|}{ Hemodynamic status } \\
\hline Heart rate, beats/min & $115(97-135)$ & $121(99-143)$ & $120(101-141)$ & .76 \\
\hline Mean arterial pressure, $\mathrm{mm} \mathrm{Hg}$ & $69(59-85)$ & $72(62-80)$ & $72(62-83)$ & .96 \\
\hline \multicolumn{5}{|l|}{ WOB indices } \\
\hline \multicolumn{5}{|l|}{$\mathrm{P}_{\mathrm{es}}$ derived data } \\
\hline Swing $\mathrm{P}_{\mathrm{es}}, \mathrm{cm} \mathrm{H}_{2} \mathrm{O}$ & $3.9(1.7-6.2)$ & $5.5(2.7-8.5)$ & $3.1(1.1-5.5)$ & .33 \\
\hline $\mathrm{PTP}_{\mathrm{es}} / \mathrm{min}, \mathrm{cm} \mathrm{H}_{2} \mathrm{O} \times \mathrm{s} / \mathrm{min}$ & $23(5-89)$ & $83(24-110)$ & $31(10-69)$ & .75 \\
\hline \multicolumn{5}{|l|}{$\mathrm{EA}_{\mathrm{di}}$ derived data } \\
\hline Peak EA $\mathrm{DI}, \mu \mathrm{V}$ & $7.5(3.2-16.3)$ & $15.9(5.2-22.1)$ & $9.1(3.0-14.4)$ & .059 \\
\hline Neuromechanical efficiency $\left(\Delta \mathrm{P}_{\mathrm{es}} / \Delta \mathrm{EA}_{\mathrm{di}}\right)$ & $0.6(0.4-1.1)$ & $0.8(0.3-1.0)$ & $0.6(0.2-1.5)$ & .56 \\
\hline Neuroventilatory efficiency $\left(\mathrm{V}_{\mathrm{T}} / \Delta \mathrm{EA}_{\mathrm{di}}\right)$ & $5.1(2.2-21.4)$ & $3.3(1.4-6.7)$ & $5.2(1.8-26.2)$ & .30 \\
\hline \multicolumn{5}{|l|}{ Indirect calorimeter derived data } \\
\hline$\dot{\mathrm{V}}_{\mathrm{O}_{2}} / \mathrm{kg}, \mathrm{mL} / \mathrm{kg} / \mathrm{min}$ & $3.6(3.1-4.6)$ & $3.8(3.0-5.2)$ & $3.8(3.2-5.2)$ & .98 \\
\hline Respiratory load $\dot{\mathrm{V}}_{\mathrm{O}_{2}} / \mathrm{kg}, \mathrm{mL} / \mathrm{kg} / \mathrm{min}$ & NA & $-0.2(-0.5$ to 0.44$)$ & NA & \\
\hline$\dot{\mathrm{V}}_{\mathrm{CO}_{2}} / \mathrm{kg}, \mathrm{mL} / \mathrm{kg} / \mathrm{min}$ & $2.8(2.3-3.3)$ & $2.5(2.1-3.6)$ & $2.5(2.3-3.3)$ & .57 \\
\hline Resting energy expenditure, $\mathrm{kcal} / \mathrm{kg}$ & $23(21-29)$ & $24(19-33)$ & $23(21-33)$ & .96 \\
\hline Respiratory quotient & $0.71(0.69-0.78)$ & $0.72(0.68-0.78)$ & $0.70(0.65-0.77)$ & .70 \\
\hline $\begin{array}{l}\mathrm{SBT}=\text { spontaneous breathing trial } \\
\mathrm{IQR}=\text { interquartile range } \\
\mathrm{V}_{\mathrm{T}}=\text { tidal volume } \\
\dot{\mathrm{V}}_{\mathrm{E}}=\text { minute volume } \\
\mathrm{RSBI} \text { = rapid shallow breathing index } \\
\text { WOB = work of breathing } \\
\mathrm{P}_{\mathrm{es}}=\text { esophageal pressure } \\
\mathrm{PTP}_{\mathrm{es}}=\text { esophageal pressure-pressure-time product } \\
\mathrm{EA}_{\mathrm{di}}=\text { electrical activity of the diaphragm } \\
\dot{\mathrm{V}}_{\mathrm{O}_{2}}=\text { oxygen consumption } \\
\mathrm{NA}=\text { not applicable } \\
\dot{\mathrm{V}}_{\mathrm{CO}_{2}}=\text { carbon dioxide production }\end{array}$ & & & & \\
\hline
\end{tabular}

respiratory quotient measured by indirect calorimetry was $0.71(0.69-0.78)$.

\section{Correlations Between $\mathbf{P}_{\mathrm{es}}, \mathbf{E} \mathbf{A}_{\mathrm{di}}$, and $\dot{\mathbf{V}}_{\mathrm{O}_{2}}$}

Overall, changes in $\dot{\mathrm{V}}_{\mathrm{O}_{2}}$ were not correlated with the changes observed with $\mathrm{PTP}_{\mathrm{es}}$ and peak $\mathrm{EA}_{\mathrm{di}}\left(\mathrm{R}^{2}=0.05\right.$ and $\mathrm{R}^{2}=0.01$, respectively). Similarly, only a poor correlation was observed between changes in $P_{\text {es }}$ and changes in $\mathrm{EA}_{\mathrm{di}}\left(\mathrm{R}^{2}=0.3\right)$ (Fig. 2).

\section{Outcome}

SBT was considered a success in 20 subjects (100\%), and extubation was successful in 17 subjects (89\%). One subject was not extubated and died after limitation of life support treatment. Median (IQR) duration of mechanical ventilation and stay in the pediatric ICU were 10 (4-14) d and 18 (7-42) d, respectively. After extubation, 9 subjects $(45 \%)$ required no respiratory support, whereas $2(10 \%)$ were reintubated, and $8(40 \%)$ were on noninvasive respiratory support within $1 \mathrm{~h}$ of extubation. The pattern of $\mathrm{PTP}_{\mathrm{es}}, \mathrm{EA}_{\mathrm{di}}$, and $\dot{\mathrm{V}}_{\mathrm{O}_{2}}$ during the SBT were not associated with extubation failure, although the number of subjects was limited.

\section{Discussion}

In this series of 20 children who were critically ill, we observed that SBT in CPAP was associated with a nonsignificant increase in $\mathrm{P}_{\mathrm{es}}$ derived indices of effort of breathing and of $\mathrm{EA}_{\mathrm{di}}$. However, the respiratory load $\dot{\mathrm{V}}_{\mathrm{O}_{2}}$ measure- 

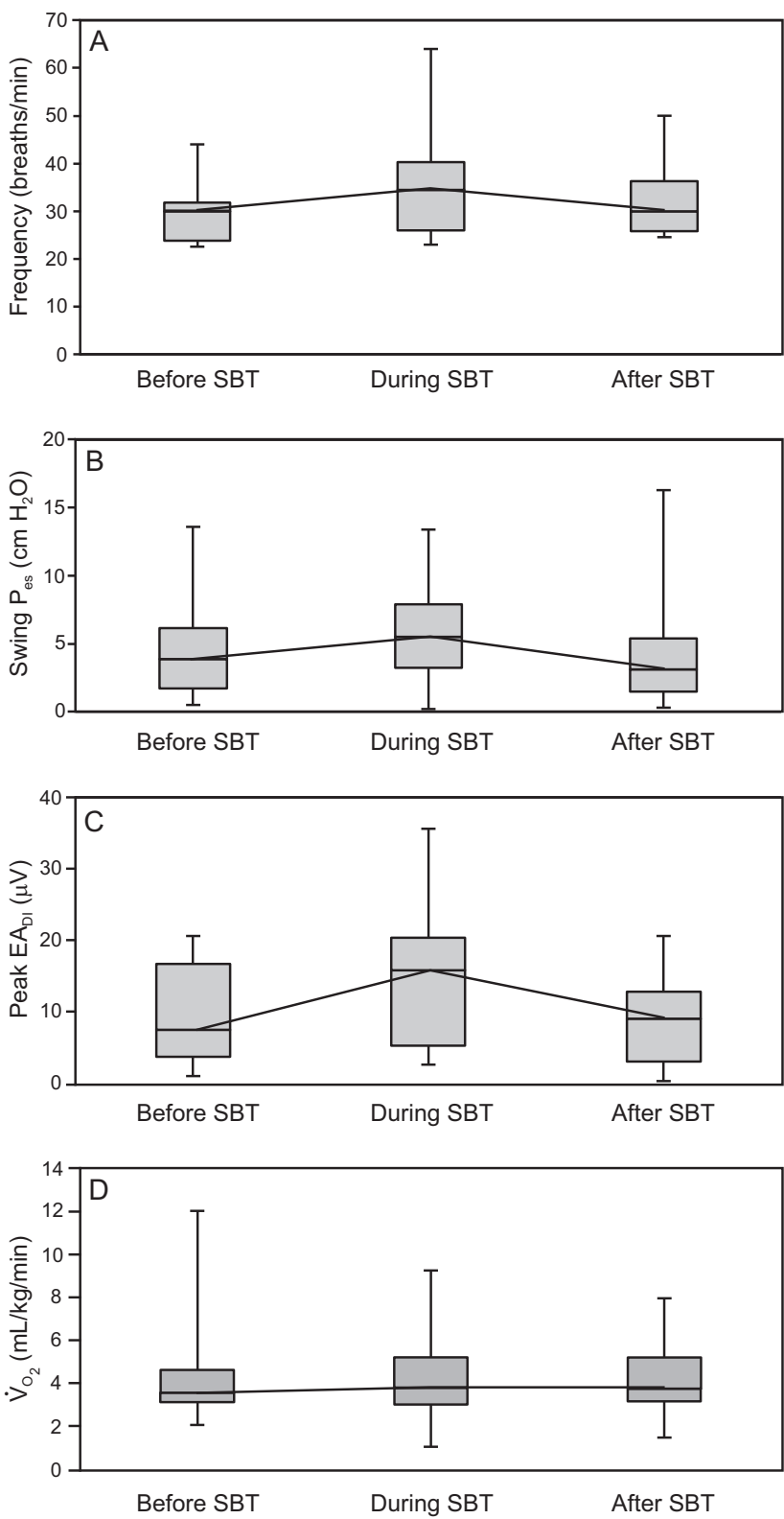

Fig. 1. Work of breathing before, during and after SBT, assessed by breathing frequency $(A)$, swing peak esophageal pressure $\left(P_{e s}\right.$, $B)$, peak electrical activity of the diaphragm $\left(E_{\mathrm{di}}, \mathrm{C}\right)$, and oxygen consumption $\left(\dot{V}_{\mathrm{O}_{2}}, \mathrm{D}\right)$. SBT = spontaneous breathing trial.

ments were stable during the maneuver. In children, the benefit of weaning protocols, including SBT, to shorten the duration of ventilation has been demonstrated, ${ }^{17}$ and the recent consensus conference on pediatric ARDS recommends that SBT and/or extubation readiness tests should be performed. ${ }^{18}$ For monitoring patient-ventilator interactions during SBT, clinicians mostly rely on patient breathing patterns and waveforms that are available on most ventilators.

However, several difficulties remain to assess the patient's contribution to the work of breathing with usual clinical monitoring during mechanical ventilation. ${ }^{19}$ Mea- surements of $\mathrm{P}_{\mathrm{es}}$ and $\mathrm{EA}_{\mathrm{di}}$ provide the clinicians with a bedside evaluation of respiratory effort from 2 different points of view. Assessment of $\mathrm{P}_{\mathrm{es}}$ is the reference method to measure the pressure generated by the patient's inspiratory muscles. The direct monitoring of respiratory muscle function by $\mathrm{P}_{\mathrm{es}}$ has been shown to be helpful in titrating ventilator support in different pathologies ${ }^{20}$ and, as Jubran and Tobin ${ }^{5}$ showed in adults, the $\mathrm{P}_{\mathrm{es}}$ trend during an SBT can provide an accurate prediction of weaning outcome.

However, $\mathrm{EA}_{\mathrm{di}}$ gives the clinician a bedside evaluation of diaphragm activity. ${ }^{21} \mathrm{EA}_{\mathrm{di}}$ can be considered as a parameter that reflects patient ventilatory drive, and it provides a continuous indirect reflection of the evolution in work of breathing. ${ }^{22}$ Because adequate diaphragmatic function is paramount for weaning success, the relevance of monitoring $\mathrm{EA}_{\mathrm{di}}$ during the weaning process has also been described. ${ }^{23}$ Wolf et $\mathrm{al}^{7}$ observed that the ability to generate a higher diaphragmatic activity for the same $\mathrm{V}_{\mathrm{T}}$ in pressure-support ventilation was a predictor of successful extubation. Combining $\mathrm{EA}_{\mathrm{di}}$ and $\mathrm{V}_{\mathrm{T}}$ in the neuroventilatory index is an interesting concept because the comparison of ventilatory demand with mechanical output provides information on diaphragmatic efficiency.

Our initial hypothesis was that $\dot{\mathrm{O}}_{\mathrm{O}_{2}}$ provided at the bedside of children who are critically ill by indirect calorimetry could provide a reliable and less-invasive method to estimate the change in the work of breathing during weaning from conventional ventilation. We reasonably assumed that no confounding factor except increasing the work of breathing could induce an increase in $\dot{\mathrm{V}}_{\mathrm{O}_{2}}$ during SBT. We, therefore, chose to record 3 periods of $30 \mathrm{~min}$, during which time, the underlying metabolic condition could not change, as suggested in a previous study. ${ }^{12}$

Many investigators, rather than focusing on mechanical muscle function, evaluated the role of the respiratory load $\dot{\mathrm{V}}_{\mathrm{O}_{2}}$ as a predictor of weaning success, ${ }^{9,24}$ and other investigators reported that the respiratory load $\dot{\mathrm{V}}_{\mathrm{O}_{2}}$ was closely correlated to PTP. ${ }^{25}$ In children, the use of indirect calorimetry for respiratory purposes is scarcely reported. ${ }^{26}$ In a few studies, $\dot{\mathrm{V}}_{\mathrm{O}_{2}}$ has been measured in children on mechanical ventilation in different clinical conditions to assess the effects of therapeutics such as neuromuscular blockers $^{27}$ or inhaled salbutamol. ${ }^{28}$ To our knowledge, $\dot{\mathrm{V}}_{\mathrm{O}_{2}}$ measurement during weaning from pediatric mechanical ventilation has never been studied.

Compared with measurements from $\mathrm{P}_{\mathrm{es}}$ and $\mathrm{EA}_{\mathrm{di}}$, the respiratory load $\dot{\mathrm{V}}_{\mathrm{O}_{2}}$ did not tend to accurately reflect changes in work of breathing. We could expect a respiratory load $\dot{\mathrm{V}}_{\mathrm{O}_{2}}$ of $\sim 10 \%$ of $\dot{\mathrm{V}}_{\mathrm{O}_{2}}$ according to the study by Hoher et al ${ }^{29}$ who found that subjects on assisted ventilation spent $11 \%$ more energy than those on controlled ventilation, as supported by another study. ${ }^{12}$ Yet, we found, in the present study, that the respiratory load $\dot{\mathrm{V}}_{\mathrm{O}_{2}}$ was not influenced by ventilator mode, in agree- 

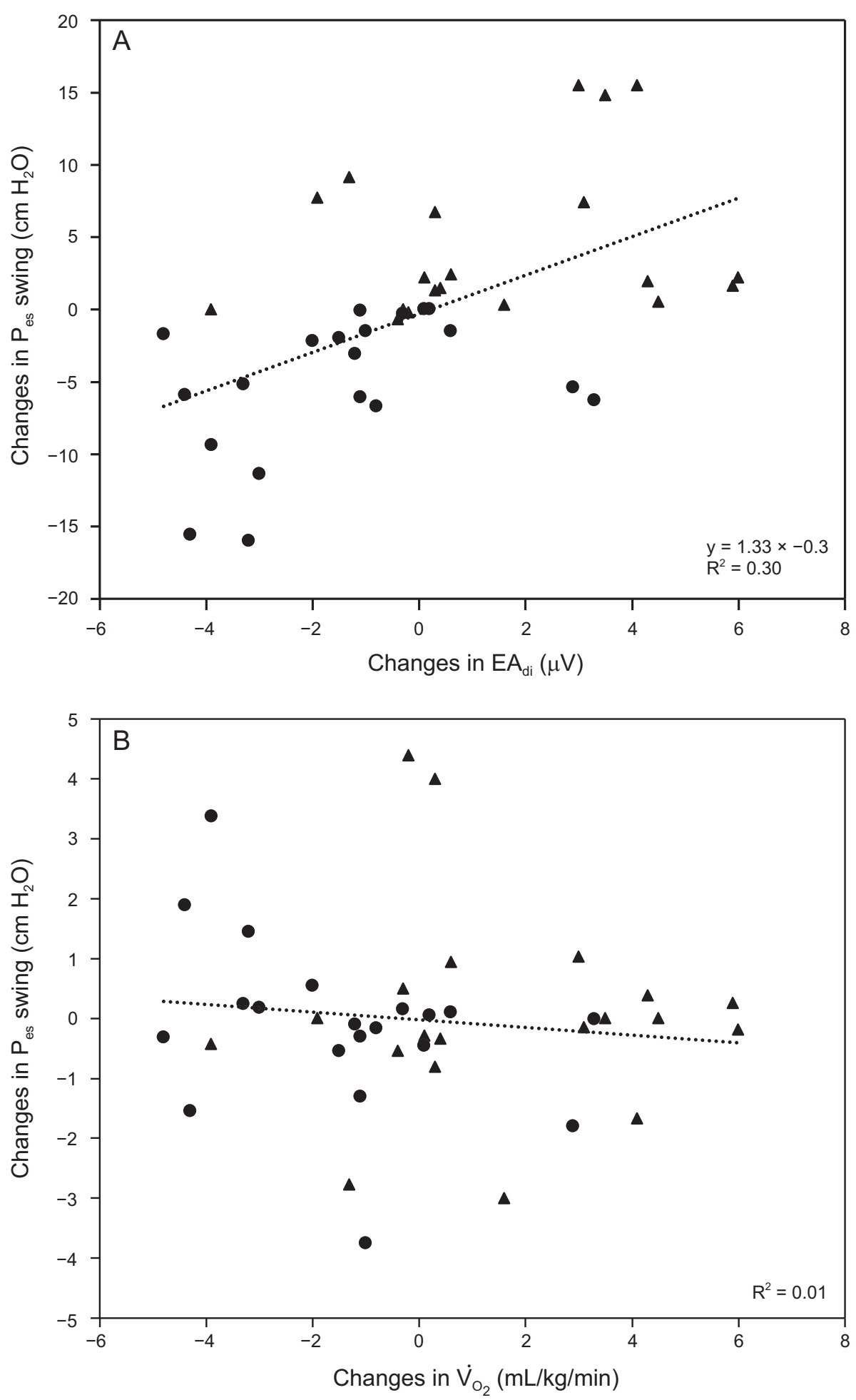

Fig. 2. Relationship between the changes of swing ventilatory mechanical action (esophageal pressure $\left[P_{\text {es }}\right]$ ) vs peak ventilatory demand (electrical activity of the diaphragm $\left.\left[E_{\mathrm{di}}\right]\right)(\mathrm{A})$ and swing $\mathrm{P}_{\mathrm{es}}$ vs oxygen consumption $\left(\dot{\mathrm{V}}_{\mathrm{O}_{2}}\right)(\mathrm{B})$ from conventional settings to spontaneous breathing trial (SBT) $(\mathbf{\Lambda})$ and from SBT to previous settings $(\bullet)$.

ment with the study published by Briassoulis et $\mathrm{al}^{30}$ in a population of 11 children who were critically ill and on mechanical ventilation.
We suggested several hypotheses to analyze this finding. First, the subjects were relatively stable and had a low level of support before SBT. In that context, the respira- 
tory load $\dot{\mathrm{V}}_{\mathrm{O}_{2}}$ may not be as sensitive as $\mathrm{P}_{\mathrm{es}}$ or $\mathrm{EA}_{\mathrm{di}}$ to detect a small change in the work of breathing. According to the study performed by Frankenfield and Ashcraft, ${ }^{31}$ measurements from the Vmax Encore Calorimeter can be biased by $5 \%$ in the same subject. One may speculate that, in patients with worse respiratory function, the results might have been different. Second, this finding could be explained by the great heterogeneity of our population, in terms of pathologies, mode of ventilation, ventilator settings, duration of ventilation, time of inclusion, and degree of sedation. ${ }^{30}$ Third, SBT may induce changes in functional residual capacity, which results in changes in spirometer volume unassociated with $\dot{\mathrm{V}}_{\mathrm{O}_{2}}$.

Also, it is important to note that agitation or distress that may accompany a difficult SBT can also contribute to the $\dot{\mathrm{V}}_{\mathrm{O}_{2}}$ increase. In our study, the changes in $\dot{\mathrm{V}}_{\mathrm{O}_{2}}$ were small, and similar values of COMFORT behavior scores were observed during the 3 periods of the protocol (before, during, and after SBT), which made it difficult to assess this potential relationship. Further work is clearly needed to assess the value of indirect calorimetry during the weaning phase in other contexts and, in particular, earlier in the course of ventilation and in patients with a worse respiratory condition and a higher rate of SBT failure.

Besides the main study goal, we, interestingly, observed absolute $\dot{\mathrm{V}}_{\mathrm{O}_{2}}$ values that were lower than previously reported. ${ }^{26,32}$ Most of these studies were performed at the early stage of the disease..$^{33}$ Moreover, most of the subjects in those studies were admitted after trauma, and some of them received nutritional therapy, which could explain such difference. In our study, because we performed indirect calorimetry measurements during the weaning phase, we hypothesized that the metabolic rate was low in the recovery period. Although we consider observed $\dot{\mathrm{V}}_{\mathrm{O}_{2}}$ values as true, we cannot exclude that confounding factors could explain such results. First, although we excluded patients with $\mathrm{F}_{\mathrm{IO}_{2}}>0.6$ or cuff leaks $>10 \%$, values could be less accurate in subjects with $\mathrm{F}_{\mathrm{IO}_{2}}>0.4$ or cuff leaks $>5 \% .{ }^{34}$ In addition, even though we used a standardized and validated approach for indirect calorimetry measurements, we could not rule out the possibility of inaccurate measurements or technical problems. ${ }^{35}$

Both $\mathrm{EA}_{\mathrm{di}}$ and $\mathrm{P}_{\mathrm{es}}$ are well-known parameters that indirectly reflect respiratory muscle function. Previous studies show a tight correlation between $\mathrm{EA}_{\mathrm{di}}$ and $\mathrm{P}_{\mathrm{es}}{ }^{22,36}$ However, there is high inter-individual variability. ${ }^{36}$ In our study, the changes observed between the 3 periods for these 2 variables were relatively small, and the data were limited, which likely explained the poor correlation observed, due to limited statistical power. This can also reveal that the effort needed to breathe before SBT was not significantly increased over normal physiologic conditions, which would not have been the case if measurements had been performed earlier in the course of mechanical ventilation.
Of note, the relationship between $\mathrm{EA}_{\mathrm{di}}$ and $\mathrm{P}_{\mathrm{es}}$ can also be affected by sedation ${ }^{37}$ or by the level of assistance. ${ }^{38}$ These factors, in addition to the great heterogeneity in our population, could also explain the moderate correlation between $\mathrm{EA}_{\mathrm{di}}$ and PTP. An impaired neuromuscular coupling ${ }^{39}$ seemed unlikely in these subjects with a near-normal respiratory condition. Also, our findings regarding the difference between predicted and measured resting energy expenditure were in agreement with those reported elsewhere. Indeed, several studies showed that predictive equations overestimated resting energy expenditure in children who were critically ill and with various clinical situations. ${ }^{32,40}$ Our results tended to confirm that such equations could not substitute for indirect calorimetry measurement of resting energy expenditure.

There were several limitations in the present study. This was a single-center study, which tends to limit its generalizability. The sample size was small and, therefore, this study may have been underpowered to demonstrate the correlation between the variables and to show any significant impact of SBT on the indices that reflected the effort of breathing. The sample size had been estimated when we hypothesized a greater impact of SBT and a high correlation between the 3 methods of work of breathing assessment. We performed measurements during daytime and weekdays only, which could lead to a selection bias. The study population was heterogeneous in terms of reasons for admission, duration of mechanical ventilation, age, and degree of sedation of the patients. This may lead to different respiratory behavior during weaning from mechanical ventilation. However, the population reflected a usual pediatric ICU population.

In addition, work of breathing indices were assessed during a 30-min SBT, whereas some investigators have suggested a longer extubation readiness test. ${ }^{20}$ Nevertheless, significant changes in respiratory mechanics occur rapidly after modification of ventilator settings. Regarding the $\mathrm{P}_{\mathrm{es}}$ measurement, due to the unique catheter used to monitor both $\mathrm{EA}_{\mathrm{di}}$ and $\mathrm{P}_{\mathrm{es}}$, it was not possible to independently adjust the position specifically for $\mathrm{P}_{\mathrm{es}}$, although the position in the lower esophagus was relatively guaranteed by the probe design. It was possible that this induced a suboptimal $\mathrm{P}_{\mathrm{es}}$ signal in some subjects. Noteworthy, the impact of the position was likely the same during the 3 ventilation periods. Finally, we did not assess respiratory muscle function after extubation.

\section{Conclusions}

In these children who were critically ill, an SBT on CPAP induced a moderate and nonsignificant increase in the work of breathing, as reflected by the respiratory drive with $\mathrm{EA}_{\mathrm{di}}$ and by respiratory mechanics with $\mathrm{P}_{\mathrm{es}}$. In this specific population with relatively stable respiratory sta- 
tus, the $\dot{\mathrm{V}}_{\mathrm{O}_{2}}$ measurement was not a sensitive parameter to detect an increase in respiratory muscle activity during the SBT. The interest of this monitoring technology should be further evaluated, in particular, in patients with a higher work of breathing.

\section{ACKNOWLEDGMENTS}

The authors thank the patients and their families for their willingness to participate in our study. We thank Mariana Dumitrascu, Mary-Ellen French, and Jouher Nait for their help in the screening and enrollment process, Lucy Clayton for the study management support, the respiratory therapists for their logistic help, the pediatric ICU fellows, attending health-care providers, and pediatric ICU nurses for their collaboration.

\section{REFERENCES}

1. Kneyber MC, Zhang H, Slutsky AS. Ventilator-induced lung injury. Similarity and differences between children and adults. Am J Respir Crit Care Med 2014;190(3):258-265.

2. Jaber S, Petrof BJ, Jung B, Chanques G, Berthet JP, Rabuel C, et al. Rapidly progressive diaphragmatic weakness and injury during mechanical ventilation in humans. Am J Respir Crit Care Med 2011; 183(3):364-371.

3. Newth CJ, Venkataraman S, Willson DF, Meert KL, Harrison R, Dean JM, et al; Eunice Shriver Kennedy National Institute of Child Health and Human Development Collaborative Pediatric Critical Care Research Network. Weaning and extubation readiness in pediatric patients. Pediatr Crit Care Med 2009;10(1):1-11.

4. Teixeira C, Teixeira PJ, de Leon PP, Oliveira ES. Work of breathing during successful spontaneous breathing trial. J Crit Care 2009;24(4): 508-514.

5. Jubran A, Tobin MJ. Pathophysiologic basis of acute respiratory distress in patients who fail a trial of weaning from mechanical ventilation. Am J Respir Crit Care Med 1997;155(3):906-915.

6. Khemani RG, Sekayan T, Hotz J, Flink RC, Rafferty GF, Iyer N, Newth CJL. Risk factors for pediatric extubation failure: the importance of respiratory muscle strength. Crit Care Med 2017;45(8): e798-e805.

7. Wolf GK, Walsh BK, Green ML, Arnold JH. Electrical activity of the diaphragm during extubation readiness testing in critically ill children. Pediatr Crit Care Med 2011;12(6):e220-e224.

8. Liu L, Liu H, Yang Y, Huang Y, Liu S, Beck J, et al. Neuroventilatory efficiency and extubation readiness in critically ill patients. Crit Care 2012;16(4):R143.

9. Bellani G, Foti G, Spagnolli E, Milan M, Zanella A, Greco M, et al. Increase of oxygen consumption during a progressive decrease of ventilatory support is lower in patients failing the trial in comparison with those who succeed. Anesthesiology 2010;113(2):378-385.

10. Field S, Kelly SM, Macklem PT. The oxygen cost of breathing in patients with cardiorespiratory disease. Am Rev Respir Dis 1982; 126(1):9-13.

11. Annat GJ, Viale JP, Dereymez CP, Bouffard YM, Delafosse BX, Motin JP. Oxygen cost of breathing and diaphragmatic pressure-time index. Measurement in patients with COPD during weaning with pressure support ventilation. Chest 1990;98(2):411-414.

12. dos Santos LJ, Hoff FC, Condessa RL, Kaufmann ML, Vieira SR. Energy expenditure during weaning from mechanical ventilation: is there any difference between pressure support and T-tube? J Crit Care 2011;26(1):34-41.

13. Larouche A, Massicotte E, Constantin G, Ducharme-Crevier L, Essouri S, Sinderby C, et al. Tonic diaphragmatic activity in critically ill children with and without ventilatory support. Pediatr Pulmonol 2015;50(12):1304-1312.

14. Randolph AG, Wypij D, Venkataraman ST, Hanson JH, Gedeit RG, Meert KL, et al; Pediatric Acute Lung Injury and Sepsis Investigators (PALISI) Network. Effect of mechanical ventilator weaning protocols on respiratory outcomes in infants and children: a randomized controlled trial. JAMA 2002;288(20):2561-2568.

15. Eren G, Cukurova Z, Demir G, Hergunsel O, Kozanhan B, Emir NS. Comparison of dexmedetomidine and three different doses of midazolam in preoperative sedation. J Anaesthesiol Clin Pharmacol 2011; 27(3):367-372.

16. Reeves MM, Davies PS, Bauer J, Battistutta D. Reducing the time period of steady state does not affect the accuracy of energy expenditure measurements by indirect calorimetry. J Appl Physiol (1985) 2004;97(1):130-134.

17. Foronda FK, Troster EJ, Farias JA, Barbas CS, Ferraro AA, Faria LS, et al. The impact of daily evaluation and spontaneous breathing test on the duration of pediatric mechanical ventilation: a randomized controlled trial. Crit Care Med 2011;39(11):2526-2533.

18. Pediatric Acute Lung Injury Consensus Conference Group. Pediatric acute respiratory distress syndrome: consensus recommendations from the Pediatric Acute Lung Injury Consensus Conference. Pediatr Crit Care Med 2015;16(5):428-439.

19. Colombo D, Cammarota G, Alemani M, Carenzo L, Barra FL, Vaschetto R, et al. Efficacy of ventilator waveforms observation in detecting patient-ventilator asynchrony. Crit Care Med 2011;39(11): 2452-2457.

20. Khemani RG, Hotz J, Morzov R, Flink RC, Kamerkar A, LaFortune $\mathrm{M}$, et al. Pediatric extubation readiness tests should not use pressure support. Intensive Care Med 2016;42(8):1214-1222.

21. Doorduin J, van Hees HW, van der Hoeven JG, Heunks LM. Monitoring of the respiratory muscles in the critically ill. Am J Respir Crit Care Med 2013;187(1):20-27.

22. Bellani G, Mauri T, Coppadoro A, Grasselli G, Patroniti N, Spadaro $\mathrm{S}$, et al. Estimation of patient's inspiratory effort from the electrical activity of the diaphragm. Crit Care Med 2013;41(6):1483-1491.

23. Jubran A, Grant BJ, Laghi F, Parthasarathy S, Tobin MJ. Weaning prediction: esophageal pressure monitoring complements readiness testing. Am J Respir Crit Care Med 2005;171(11):1252-1259.

24. Miwa K, Mitsuoka M, Takamori S, Hayashi A, Shirouzu K. Continuous monitoring of oxygen consumption in patients undergoing weaning from mechanical ventilation. Respiration 2003;70(6):623-630.

25. Field S, Sanci S, Grassino A. Respiratory muscle oxygen consumption estimated by the diaphragm pressure-time index. J Appl Physiol Respir Environ Exerc Physiol 1984;57(1):44-51.

26. Smallwood CD, Walsh BK, Bechard LJ, Mehta NM. Carbon dioxide elimination and oxygen consumption in mechanically ventilated children. Respir Care 2015;60(5):718-723.

27. Lemson J, Driessen JJ, van der Hoeven JG. The effect of neuromuscular blockade on oxygen consumption in sedated and mechanically ventilated pediatric patients after cardiac surgery. Intensive Care Med 2008;34(12):2268-2272.

28. Ross PA, Newth CJ, Hugen CA, Maher JK, Deakers TW. Increase in oxygen consumption after albuterol inhalation in ventilated infants and children. Pediatr Crit Care Med 2014;15(9):e389-e392.

29. Hoher JA, Zimermann Teixeira PJ, Hertz F, da S Moreira J. A comparison between ventilation modes: how does activity level affect energy expenditure estimates? JPEN J Parenter Enteral Nutr 2008;32(2):176-183.

30. Briassoulis G, Michaeloudi E, Fitrolaki DM, Spanaki AM, Briassouli E. Influence of different ventilator modes on $\mathrm{Vo}(2)$ and $\mathrm{Vco}(2)$ measurements using a compact metabolic monitor. Nutrition 2009; 25(11-12):1106-1114. 


\section{InDiReCt CALORIMETRY to Assess WOB}

31. Frankenfield DC, Ashcraft CM. Toward the development of predictive equations for resting metabolic rate in acutely ill spontaneously breathing patients. JPEN J Parenter Enteral Nutr 2017;41(7):1155-1161.

32. Vazquez Martinez JL, Martinez-Romillo PD, Diez Sebastian J, Ruza Tarrio F. Predicted versus measured energy expenditure by continuous, online indirect calorimetry in ventilated, critically ill children during the early postinjury period. Pediatr Crit Care Med 2004;5(1):19-27.

33. Oh TE, Bhatt S, Lin ES, Hutchinson RC, Low JM. Plasma catecholamines and oxygen consumption during weaning from mechanical ventilation. Intensive Care Med 1991;17(4):199-203.

34. Joosten KF, Jacobs FI, van Klaarwater E, Baartmans MG, Hop WC, Meriläinen PT, Hazelzet JA. Accuracy of an indirect calorimeter for mechanically ventilated infants and children: the influence of low rates of gas exchange and varying FIO2. Crit Care Med 2000;28(8): 3014-3018.

35. Campbell R, Branson R, Burke W, Covington J. Metabolic Measurement Using Indirect Calorimetry During Mechanical Ventilation (abstract). International Anesthesiology Clinics 1996;34(1): 111-120.
36. Sinderby C, Beck J, Spahija J, Weinberg J, Grassino A. Voluntary activation of the human diaphragm in health and disease. J Appl Physiol (1985) 1998;85(6):2146-2158.

37. Amigoni A, Rizzi G, Divisic A, Brugnaro L, Conti G, Pettenazzo A. Effects of propofol on diaphragmatic electrical activity in mechanically ventilated pediatric patients. Intensive Care Med 2015;41(10): 1860-1861.

38. Colombo D, Cammarota G, Bergamaschi V, De Lucia M, Corte FD, Navalesi P. Physiologic response to varying levels of pressure support and neurally adjusted ventilatory assist in patients with acute respiratory failure. Intensive Care Med 2008;34(11):2010-2018.

39. Sinderby C, Spahija J, Beck J, Kaminski D, Yan S, Comtois N, Sliwinski P. Diaphragm activation during exercise in chronic obstructive pulmonary disease. Am J Respir Crit Care Med 2001; 163(7):1637-1641.

40. Framson CM, LeLeiko NS, Dallal GE, Roubenoff R, Snelling LK, Dwyer JT. Energy expenditure in critically ill children. Pediatr Crit Care Med 2007;8(3):264-267.

This article is approved for Continuing Respiratory Care Education credit. For information and to obtain your CRCE

(free to AARC members) visit www.rcjournal.com

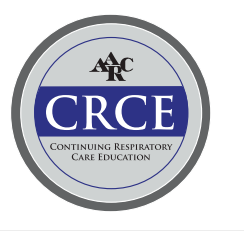

